Supporting Information

\title{
The Influence of Anion Structure on the Ionic Liquids/Au (100) Interface by Molecular Dynamics Simulations
}

\author{
Yue Wang ${ }^{1,2,3}$, Guocai Tian ${ }^{1,2 *}$
}

1State Key Laboratory of Complex Non-ferrous Metal Resource Clean Utilization, Kunming University of Science and Technology, Yunnan, Kunming, 650093, China;

2 Faculty of Metallurgical and Energy Engineering, Kunming University of Science and Technology, Kunming, 650093, China;

3 Yunnan Open University, Kunming, 650223, China

* Address correspondence to tiangc@kust.edu.cn; tiangc01@163.com 


\section{S1. The interaction energy between the particles in $[\mathrm{Bmim}] \mathrm{BF}_{4} / \mathrm{Au}(100),[\mathrm{Bmim}] \mathrm{PF}_{6} / \mathrm{Au}$}

\section{(100) and [Bmim]TFSI/Au (100)}

Table S1 The interaction energy between the particles in $\left[\mathrm{Bmim}_{\mathrm{B}} \mathrm{BF}_{4} / \mathrm{Au}(100)\right.$

\begin{tabular}{|c|c|c|c|c|c|c|c|c|c|}
\hline$\sigma$ & $\begin{array}{c}\text { Interaction } \\
\text { particles }\end{array}$ & $\begin{array}{c}E \\
(\mathrm{~kJ} / \mathrm{mol})\end{array}$ & RSD & $\begin{array}{c}\text { Interaction } \\
\text { particles }\end{array}$ & $\begin{array}{c}E \\
(\mathrm{~kJ} / \mathrm{mol})\end{array}$ & RSD & $\begin{array}{c}\text { Interaction } \\
\text { particles }\end{array}$ & $\begin{array}{c}E \\
(\mathrm{~kJ} / \mathrm{mol})\end{array}$ & RSD \\
\hline $0 \mathrm{e}$ & \multirow{9}{*}{$\begin{array}{c}\mathrm{Au}(100) / \\
{[\mathrm{Bmim}] \mathrm{BF}_{4}}\end{array}$} & -96.64 & 0.009 & \multirow{9}{*}{$\begin{array}{l}\mathrm{Au}(100) / \\
\mathrm{BBmim}^{+}\end{array}$} & -73.50 & 0.006 & \multirow{9}{*}{$\begin{array}{c}\mathrm{Au}(100) / \\
\mathrm{BF}_{4}^{-}\end{array}$} & -23.14 & 0.017 \\
\hline $2 \mathrm{e}$ & & -103.62 & 0.009 & & 62.46 & 0.006 & & -165.73 & 0.000 \\
\hline $4 \mathrm{e}$ & & -104.23 & 0.002 & & 203.82 & 0.001 & & -308.04 & 0.001 \\
\hline $6 \mathrm{e}$ & & -121.56 & 0.043 & & 331.14 & 0.012 & & -452.71 & 0.004 \\
\hline $8 \mathrm{e}$ & & -144.58 & 0.080 & & 452.46 & 0.021 & & -590.28 & 0.019 \\
\hline$-2 \mathrm{e}$ & & -93.94 & 0.012 & & -209.29 & -0.008 & & 115.63 & 0.001 \\
\hline$-4 \mathrm{e}$ & & -103.24 & 0.059 & & -349.77 & -0.011 & & 246.52 & 0.011 \\
\hline$-6 e$ & & -142.54 & 0.060 & & -507.04 & 0.002 & & 364.50 & 0.022 \\
\hline$-8 \mathrm{e}$ & & -172.72 & 0.045 & & -643.50 & 0.005 & & 470.25 & 0.013 \\
\hline
\end{tabular}

Table S2 The interaction energy between the particles in $[\mathrm{Bmim}] \mathrm{PF}_{6} / \mathrm{Au}(100)$

\begin{tabular}{cccccccccc}
\hline$\sigma$ & $\begin{array}{c}\text { Interaction } \\
\text { particles }\end{array}$ & $\begin{array}{c}E \\
(\mathrm{~kJ} / \mathrm{mol})\end{array}$ & $\mathrm{RSD}$ & $\begin{array}{c}\text { Interaction } \\
\text { particles }\end{array}$ & $\begin{array}{c}E \\
(\mathrm{~kJ} / \mathrm{mol})\end{array}$ & $\mathrm{RSD}$ & $\begin{array}{c}\text { Interaction } \\
\text { particles }\end{array}$ & $\begin{array}{c}E \\
(\mathrm{~kJ} / \mathrm{mol})\end{array}$ & $\mathrm{RSD}$ \\
\hline $0 \mathrm{e}$ & & -107.18 & 0.003 & & -75.59 & 0.004 & & -31.59 & 0.018 \\
$\mathrm{e}$ & & -104.94 & -0.003 & & 65.41 & 0.005 & & -170.35 & -0.001 \\
$4 \mathrm{e}$ & & -112.02 & -0.005 & & 198.38 & 0.005 & & -310.37 & -0.001 \\
$6 \mathrm{e}$ & $\mathrm{Au}(100) /$ & -146.06 & -0.009 & $\mathrm{Au}(100) /$ & 303.98 & 0.005 & $\mathrm{Au}(100) /$ & -450.04 & -0.006 \\
$8 \mathrm{e}$ & {$\left[{\mathrm{Bmim}] \mathrm{PF}_{6}}\right.$} & -160.91 & -0.055 & {$[\mathrm{Bmim}]^{+}$} & 431.54 & 0.020 & $\mathrm{PF}_{6}-$ & -592.47 & 0.000 \\
$-2 \mathrm{e}$ & & -117.95 & -0.013 & & -225.10 & -0.001 & & 106.43 & 0.000 \\
$-4 \mathrm{e}$ & & -113.67 & -0.003 & & -352.39 & -0.004 & & 238.72 & 0.005 \\
$-6 \mathrm{e}$ & & -156.08 & -0.011 & & -505.29 & -0.005 & & 349.21 & 0.005 \\
\hline
\end{tabular}




\begin{tabular}{lllllll}
\hline$-8 \mathrm{e}$ & -186.80 & -0.027 & -647.41 & -0.007 & 460.60 & 0.010 \\
\hline
\end{tabular}

Table S3 The interaction energy between the particles in [Bmim]TFSI/Au (100)

\begin{tabular}{|c|c|c|c|c|c|c|c|c|c|}
\hline$\sigma$ & $\begin{array}{c}\text { Interaction } \\
\text { particles }\end{array}$ & $\begin{array}{c}E \\
(\mathrm{~kJ} / \mathrm{mol})\end{array}$ & RSD & $\begin{array}{c}\text { Interaction } \\
\text { particles }\end{array}$ & $\begin{array}{c}E \\
(\mathrm{~kJ} / \mathrm{mol})\end{array}$ & RSD & $\begin{array}{c}\text { Interaction } \\
\text { particles }\end{array}$ & $\begin{array}{c}E \\
(\mathrm{~kJ} / \mathrm{mol})\end{array}$ & RSD \\
\hline $0 \mathrm{e}$ & \multirow{9}{*}{$\begin{array}{c}\mathrm{Au}(100) / \\
{[\mathrm{Bmim}] \mathrm{TFSI}}\end{array}$} & -101.68 & -0.002 & \multirow{9}{*}{$\begin{array}{l}\mathrm{Au}(100) / \\
{[\mathrm{Bmim}]^{+}}\end{array}$} & -63.54 & -0.005 & \multirow{9}{*}{$\begin{array}{l}\mathrm{Au}(100) / \\
\text { TFSI- }^{-}\end{array}$} & -38.14 & -0.013 \\
\hline $2 \mathrm{e}$ & & -83.82 & -0.006 & & 78.79 & 0.007 & & -162.60 & -0.002 \\
\hline $4 \mathrm{e}$ & & -106.81 & -0.056 & & 196.13 & 0.018 & & -302.36 & -0.006 \\
\hline $6 e$ & & -125.59 & -0.013 & & 299.20 & 0.013 & & -424.79 & -0.007 \\
\hline $8 \mathrm{e}$ & & -176.86 & -0.019 & & 392.89 & 0.005 & & -569.82 & -0.005 \\
\hline$-2 \mathrm{e}$ & & -98.80 & -0.003 & & -193.51 & -0.001 & & 94.71 & 0.003 \\
\hline$-4 \mathrm{e}$ & & -121.06 & -0.001 & & -345.13 & -0.006 & & 224.68 & 0.004 \\
\hline$-6 e$ & & -163.44 & -0.035 & & -500.15 & -0.002 & & 336.71 & 0.015 \\
\hline$-8 \mathrm{e}$ & & -212.48 & -0.022 & & -613.58 & -0.006 & & 401.10 & 0.005 \\
\hline
\end{tabular}

S2. Detailed description of the mass density profile of $\left[\mathrm{Bmim}_{B} \mathrm{BF}_{4},[\mathrm{Bmim}] \mathrm{PF}_{6}\right.$ and

\section{[Bmim] TFSI at $350 \mathrm{~K}$}

As shown in Figure 4, amplitude and degree of layers are different due to different interaction in three systems. Near the neutral electrode, $[\mathrm{Bmim}] \mathrm{PF}_{6}$ system has an obvious 4-layers structures with a thickness of $2.3 \mathrm{~nm}$ due to stronger interaction between $\left[\mathrm{Bmim}^{-} \mathrm{PF}_{6}\right.$ and electrode $(-107.18 \mathrm{~kJ} / \mathrm{mol})$. Peak intensity of the first layer adjacent to electrode is about three times than the bulk $\left(3.346 \mathrm{~g} / \mathrm{cm}^{3}\right)$. Compared to above system, [Bmim]BF 4 and $[\mathrm{Bmim}] \mathrm{TFSI}$ systems forms 3-layer structures on $\mathrm{Au}$ (100) surface, which due to weaker interaction between ILs and electrode. The layer thickness is about $1.5 \mathrm{~nm}$. Meanwhile, the height of the first peaks is 2-times than that of the bulk in $[\mathrm{Bmim}] \mathrm{BF}_{4}$ and $[\mathrm{Bmim}] \mathrm{TFSI}$ systems. In addition, we also found an interesting phenomenon. The first cationic peak values closest to the electrode are about $2.64 \mathrm{~g} / \mathrm{cm}^{3}, 2.49 \mathrm{~g} / \mathrm{cm}^{3}$ and $1.57 \mathrm{~g} / \mathrm{cm}^{3}$ in $\left[\mathrm{Bmim}^{3} \mathrm{BF}_{4},[\mathrm{Bmim}] \mathrm{PF}_{6}\right.$ and $[\mathrm{Bmim}] \mathrm{TFSI}$ systems, which account for $80 \%$ of the total density peak in the $[\mathrm{Bmim}] \mathrm{BF}_{4}$ and $[\mathrm{Bmim}] \mathrm{PF}_{6}$ systems. We believe that this is due to the strong interaction between cation and electrode in the above two systems. However, the first peak of anion is about $1.49 \mathrm{~g} / \mathrm{cm}^{3}$ in $[\mathrm{Bmim}] \mathrm{TFSI}$, indicating that the total mass density at the bottom of the system is shared by cation and anion. 


\section{S3. Mass density distribution of $B, P$ and $F$ atom at $350 \mathrm{~K}$}
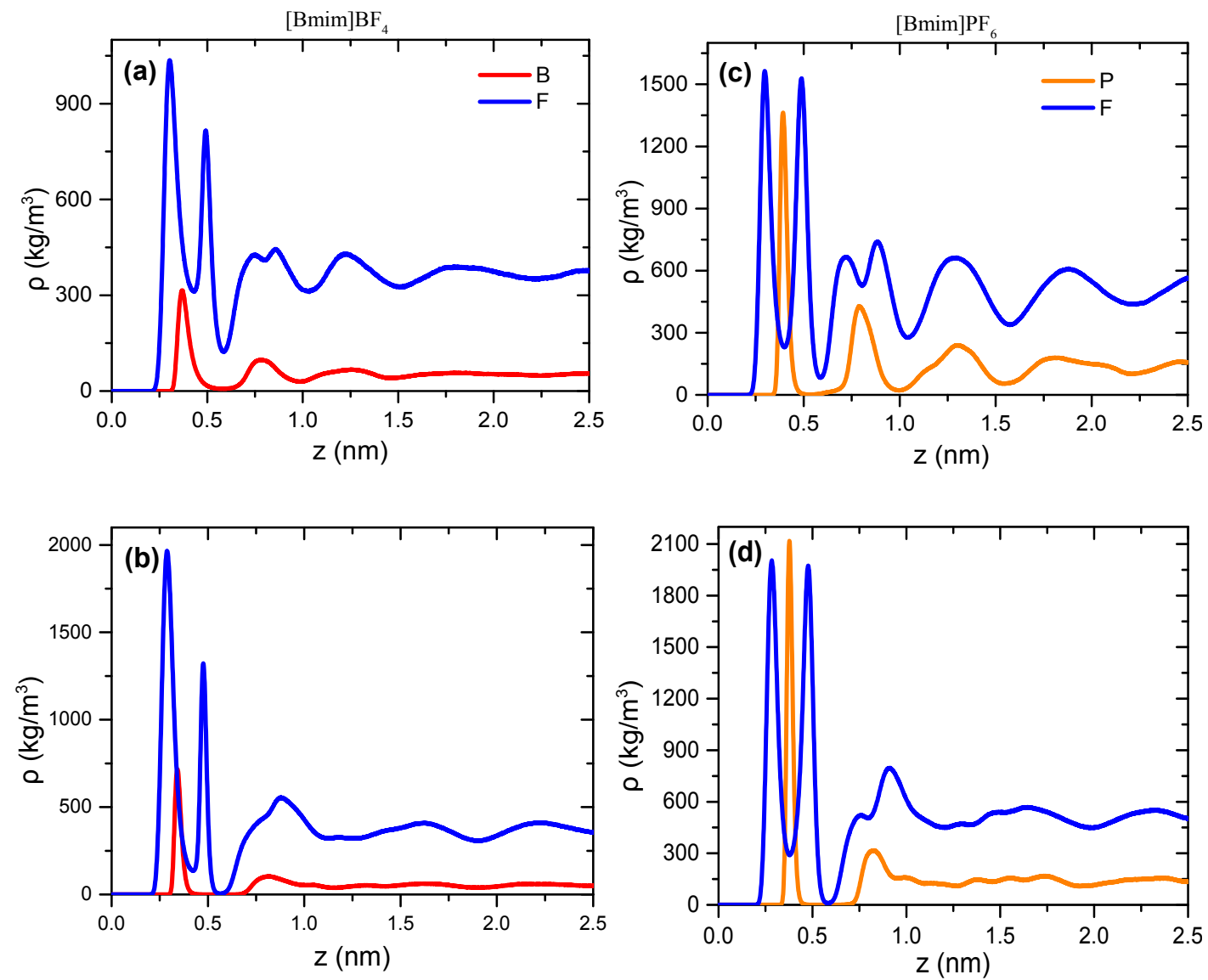

Figure S1. Mass density distribution of $\mathrm{B}, \mathrm{P}$ and $\mathrm{F}$ atom at $350 \mathrm{~K}$. The left panels (a-b) are $[\mathrm{Bmim}] \mathrm{BF}_{4}$ and right ones (c-d) are $[\mathrm{Bmim}] \mathrm{PF}_{6}$. (a) (c) represent the distribution of neutral electrode surface. (b) (d) represent the distribution of 8e surface charge. Red, orange, and blue line represents the distribution of $\mathrm{B}, \mathrm{P}$ and $\mathrm{F}$ atom, respectively. 
Figure $\mathrm{S} 1$ shows mass density distribution of $\mathrm{B}, \mathrm{P}$ and $\mathrm{F}$ atom at $350 \mathrm{~K}$ when the surface charges are $0 \mathrm{e}$ and $\pm 8 \mathrm{e}$ (atom labels was shown in Figure 1). We found that the peak of $\mathrm{F}$ atom corresponds to the position of the anion fissure exactly, regardless of the surface charge in $[\mathrm{Bmim}] \mathrm{BF}_{4}$ system. In $[\mathrm{Bmim}] \mathrm{PF}_{6}$ system, the mass density distribution of $\mathrm{F}$ atom and $\mathrm{P}$ atom is consistent with the peak position of anions. This shows that $\mathrm{P}$ atom is in the center of the anion, and the other six F atoms are evenly distributed above and below the anion in this system.

S4. The number density profile of cation/anion on charged Au (100) electrode of $\left[\mathrm{Bmim} \mathrm{PF}_{6},[\mathrm{Bmim}] \mathrm{BF}_{4}\right.$ and $[\mathrm{Bmim}] \mathrm{TFSI}$
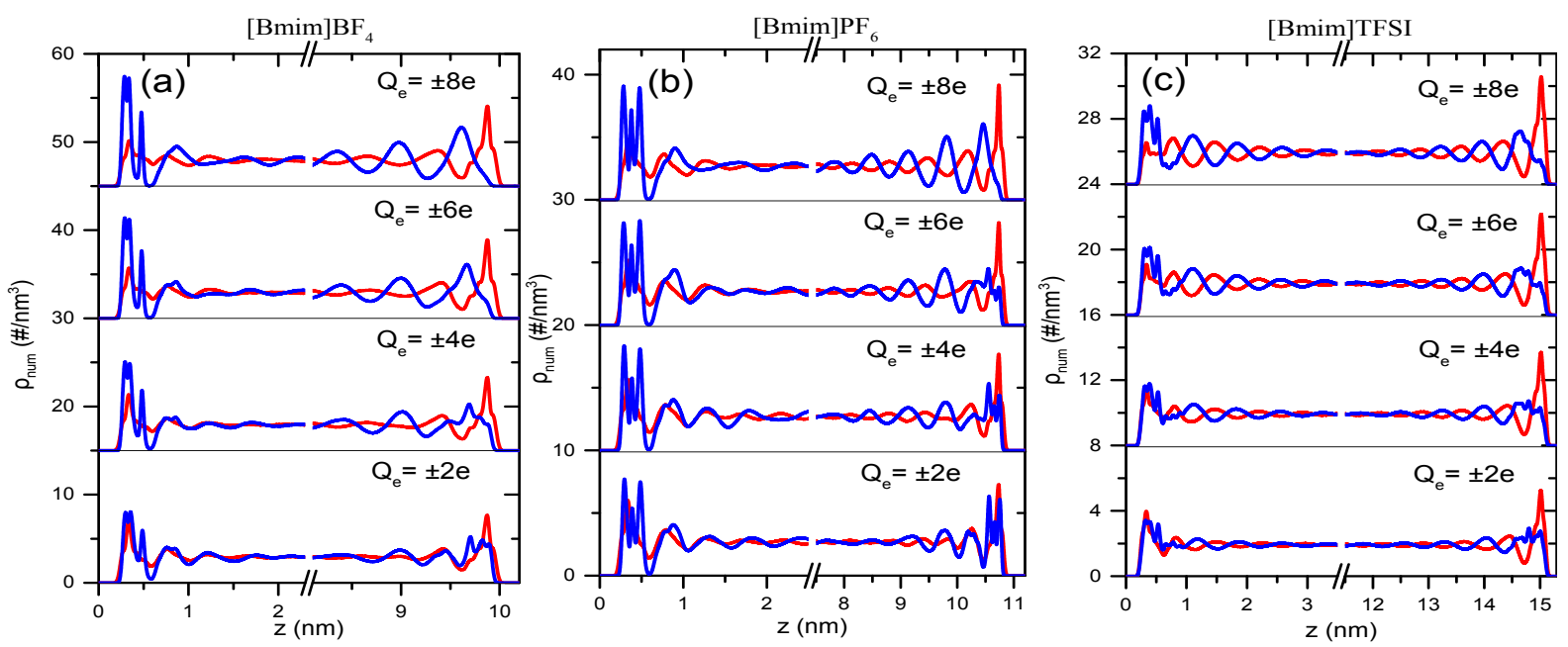

Figure S2. Number density profile of cation/anion on charged Au (100) surface of (a) $[\mathrm{Bmim}] \mathrm{BF}_{4}$, (b) $\left[\mathrm{Bmim} \mathrm{PF}_{6}\right.$ and (c) $[\mathrm{Bmim}] \mathrm{TFSI}$. The cation and anion number density distributions are represented by red and blue lines, respectively. 
S5. Number density profile of anions (B, P, NI) and cations (C1) near Au (100) electrode for $\left[\mathrm{Bmim}_{\mathrm{B}} \mathrm{BF}_{4},[\mathrm{Bmim}] \mathrm{PF}_{6}\right.$ and $[\mathrm{Bmim}]$ TFSI.
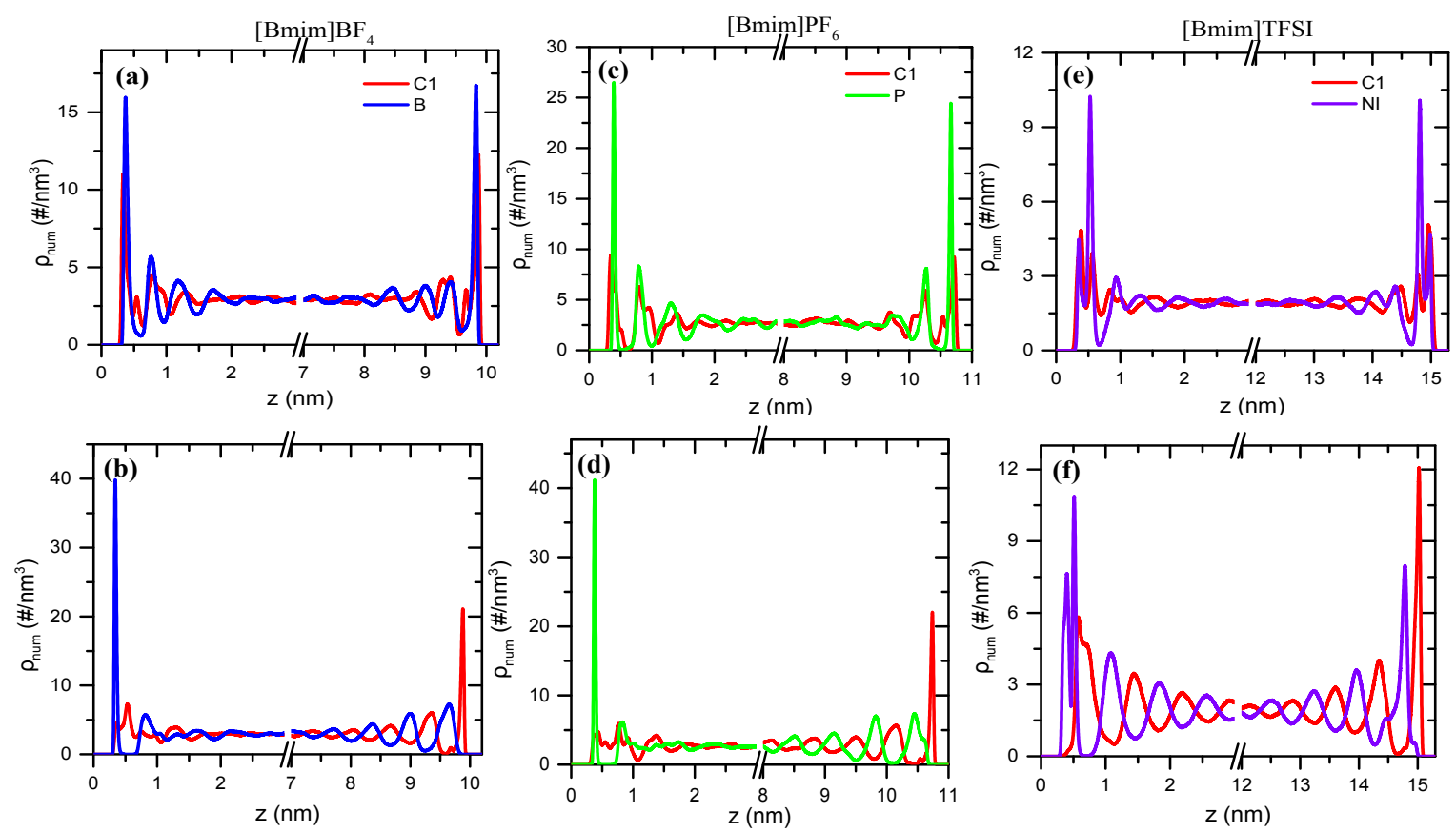

Figure S3. Number density profile of anions (B, P, NI) and cations (C1) near Au (100) electrode for (a) (b) $\left[\mathrm{Bmim}_{\mathrm{B}} \mathrm{BF}_{4}\right.$, (c) (d) $\left[\mathrm{Bmim} \mathrm{PF}_{6}\right.$, (e) (f) [Bmim]TFSI. (a) (c) (e) for surface charge densities of 0 e and (b) (d) (f) for surface charge densities of 8e. Red, blue, green, purple line represents the distribution of $\mathrm{C} 1, \mathrm{~B}, \mathrm{P}, \mathrm{NI}$, respectively.

Figure S3 shows the number density profile of anion (NI, B, P) and cation (C1) when the surface charge density is $0 \mathrm{e}$ and $\pm 8 \mathrm{e}$ (atom labels was shown in Figure 1). It is easy to find that $\mathrm{P}, \mathrm{B}$ and $\mathrm{C} 1$ atoms have single peak in $0.39 \mathrm{~nm}, 0.36 \mathrm{~nm}, 0.34 \mathrm{~nm}$ in $\left[\mathrm{Bmim}^{-} \mathrm{BF}_{4}\right.$ and $[\mathrm{Bmim}] \mathrm{PF}_{6}$ systems near neutral electrode. This is because the interaction between $\mathrm{PF}_{6}{ }^{-}$and $\mathrm{Au}$ 
(100) is stronger than that of $\mathrm{BF}_{4}^{-}$, it is easier for $\mathrm{P}$ atoms to accumulate in the first layer. The two-humped structures locate at both $\mathrm{C} 1(0.38 \mathrm{~nm}$ and $0.56 \mathrm{~nm})$ and $\mathrm{NI}(0.35 \mathrm{~nm}$ and $0.53 \mathrm{~nm})$ in [Bmim]TFSI system. The strength of NI at $0.53 \mathrm{~nm}$ is higher, indicating that anions are more likely to aggregate at $0.53 \mathrm{~nm}$. We think this is related to the different conformation of the TFSIanion. When the surface charge is $\pm 8 \mathrm{e}$, the anion aggregation is significantly increased and the cation aggregation is significantly reduced in the first layer. In addition, there are several $\mathrm{C} 1$ peaks in the first layer (this is consistent with the phenomenon observed in Figure 2) and B, P, NI atoms are closer to the anode. However, P, B, and NI atoms in the first layer of the cathode are completely expelled and many $\mathrm{C} 1$ atoms gather, forming an obvious orderly oscillation near the electrode surface. It is found that the range of oscillation at the cathode is more pronounced than at the anode. We believe that all these phenomena are caused by the increase of interaction between the anion and the electrode, while the weakening of the interaction between the electrode and the cation. 


\section{S6. Number density profile of oxygen (OS), nitrogen (NI) and fluorine (FC) atoms of TFSI-}
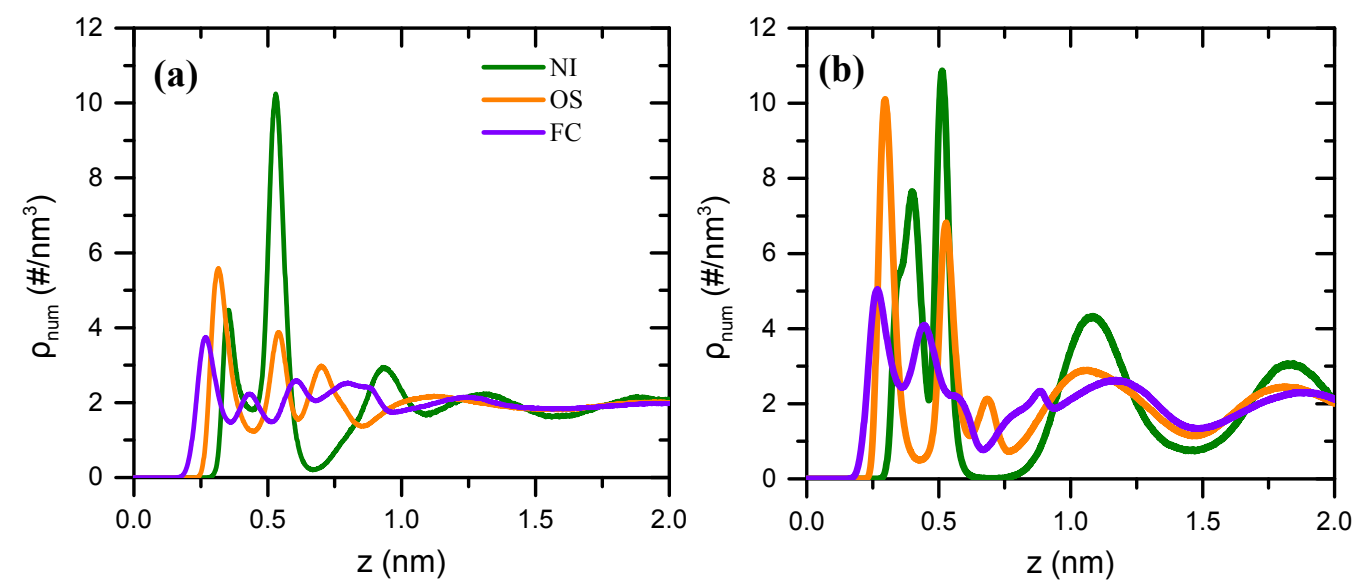

Figure S4. Number density profile of oxygen (OS), nitrogen (NI) and fluorine (FC) atoms of TFSI $^{-}$. (a) surface charge densities of 0e. (b) surface charge densities of 8e. Green, orange and purple line represents the distribution of NI, OS, and FC, respectively.

Figure S4 shows the number density profile of anion (NI, B, P) and cation $(\mathrm{C} 1)$ when the surface charge density is $0 \mathrm{e}$ and $\pm 8 \mathrm{e}$ (atom labels was shown in Figure 1). It is easy to find that $\mathrm{P}, \mathrm{B}$ and $\mathrm{Cl}$ atoms have single peak in $0.39 \mathrm{~nm}, 0.36 \mathrm{~nm}, 0.34 \mathrm{~nm}$ in $\left[\mathrm{Bmim}^{-} \mathrm{BF}_{4}\right.$ and $[\mathrm{Bmim}] \mathrm{PF}_{6}$ systems near neutral electrode. This is because the interaction between $\mathrm{PF}_{6}{ }^{-}$and $\mathrm{Au}$ (100) is stronger than that of $\mathrm{BF}_{4}^{-}$, it is easier for $\mathrm{P}$ atoms to accumulate in the first layer. The two-humped structures locate at both $\mathrm{C} 1(0.38 \mathrm{~nm}$ and $0.56 \mathrm{~nm})$ and $\mathrm{NI}(0.35 \mathrm{~nm}$ and $0.53 \mathrm{~nm})$ in [Bmim]TFSI system. The strength of NI at $0.53 \mathrm{~nm}$ is higher, indicating that anions are more likely to aggregate at $0.53 \mathrm{~nm}$. We think this is related to the different conformation of the TFSI- 
anion. When the surface charge is $\pm 8 \mathrm{e}$, the anion aggregation is significantly increased and the cation aggregation is significantly reduced in the first layer. In addition, there are several C1 peaks in the first layer (this is consistent with the phenomenon observed in Figure 2) and B, P, NI atoms are closer to the anode. However, P, B, and NI atoms in the first layer of the cathode are completely expelled and many $\mathrm{C} 1$ atoms gather, forming an obvious orderly oscillation near the electrode surface. It is found that the range of oscillation at the cathode is more pronounced than at the anode. We believe that all these phenomena are caused by the increase of interaction between the anion and the electrode, while the weakening of the interaction between the electrode and the cation.

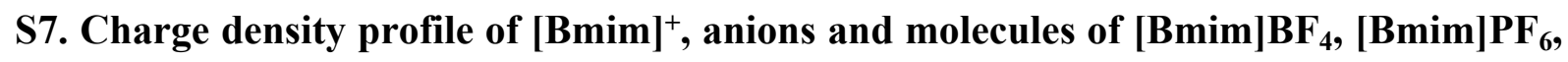
[Bmim]TFSI near charged Au (100) electrode
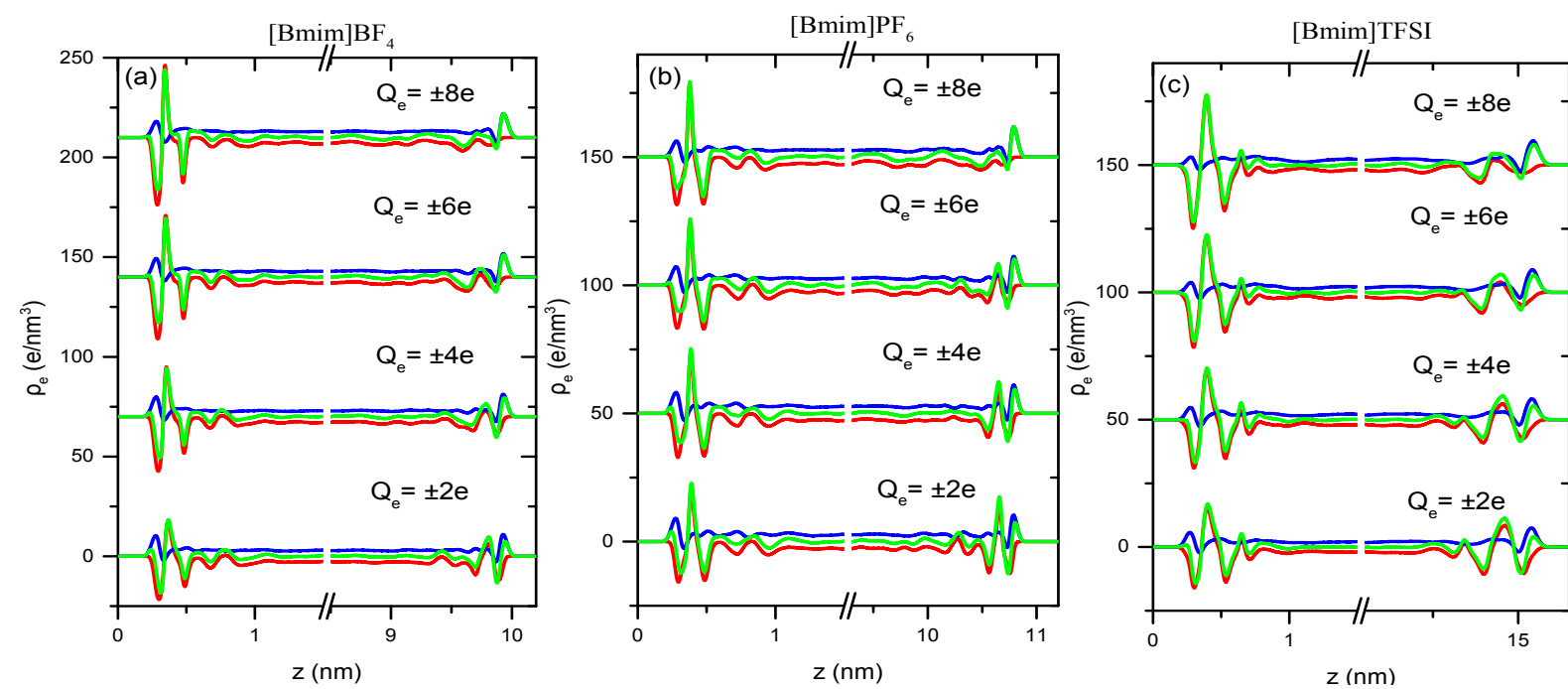

Figure S5. Charge density profile of $[\mathrm{Bmim}]^{+}$, anions and molecules of (a) $\left[\mathrm{Bmim}_{\mathrm{B}} \mathrm{BF}_{4},(\mathrm{~b})\right.$ $[\mathrm{Bmim}] \mathrm{PF}_{6}$, (c) [Bmim]TFSI near charged $\mathrm{Au}$ (100) electrode. Red, blue, and green line represents the distribution of anion, cation, and total charge, respectively.

Figure S5 shows the charge density distribution of $[\mathrm{Bmim}]^{+}$, anions and molecules of (a) $\left[\mathrm{Bmim}_{\mathrm{B}}\right] \mathrm{BF}_{4}$, (b) $[\mathrm{Bmim}] \mathrm{PF}_{6}$, (c) $[\mathrm{Bmim}] \mathrm{TFSI}$ near charged $\mathrm{Au}$ (100) electrode. We found that the fluctuations of charge density on the charged electrode are controlled by both anions and cations in three systems. Meanwhile, the fluctuation of anions is largest, while cation has lower capability ability to shield excessive local charges due to different volume characteristics and specific orientation of anions. As the surface charge increases, the charge oscillation near the 
anode increase, and the charge density fluctuation is mainly controlled by anions. [Bmim $]^{+}$ generates a slight positive charge at $0.27 \mathrm{~nm}$, which is more than neutral surface. Subsequently, the anions also produce a layer of excess positive charge, which is significantly stronger than that of the neutral electrode. The charge density oscillates less on the cathode surface than the anode surface. Due to the anions completely are discharged from the first layer, the charge density distributions are mainly controlled by cations. Specifically, an excess cation peak at $0.77 \mathrm{~nm}, 0.67 \mathrm{~nm}$ and $0.66 \mathrm{~nm}$ from the negative electrode are generated an excess cation peak in $[\mathrm{Bmim}] \mathrm{TFSI},[\mathrm{Bmim}] \mathrm{PF}_{6}$ and $[\mathrm{Bmim}] \mathrm{BF}_{4}$ systems. Subsequently, a locally excessive negative charge of anion which has similar strength is produced. Interestingly, the local charge surplus only occurs within the $1.0 \mathrm{~nm}$. When the distance is father than $1.0 \mathrm{~nm}$, the local excess charge disappears. We believe that the charge density distribution is affected by the characteristics of the ILs and electrode on the charged surface. 